\title{
Expression of the REG IV gene in ulcerative colitis
}

\author{
Apichart Nanakin ${ }^{1}$, Hirokazu Fukui ${ }^{1,2}$, Shigehiko Fujii ${ }^{1,2}$, Akira Sekikawa ${ }^{1,2}$, Naoki Kanda ${ }^{1}$, Hiroshi Hisatsune ${ }^{1}$, \\ Hiroshi Seno', Yoshitaka Konda ${ }^{1}$, Takahiro Fujimori ${ }^{2}$ and Tsutomu Chiba ${ }^{1}$
}

The regenerating gene (REG) IV gene was isolated from a cDNA library of ulcerative colitis (UC) tissues. However, its role in the pathophysiology of UC and subsequent development of colitic cancer is still unclear. We investigated the expression of the REG IV gene in UC and colitic cancer tissues and examined whether cytokines or growth factors are responsible for REG IV gene expression and whether REG IV gene induction affects cell growth and apoptosis in colon cancer cells. The expressions of REG IV and growth factor genes in UC tissues were analyzed by real time reverse transcription-polymerase chain reaction. The effects of cytokines and growth factors on REG IV gene expression were examined in SW403 cells by Northern blot analysis. The effects of REG IV gene induction on cell growth and $\mathrm{H}_{2} \mathrm{O}_{2}$-induced apoptosis were examined in DLD-1 cells by MTT and TUNEL assays, respectively. REG IV MRNA was strongly expressed in inflamed epithelium and in dysplasias and cancerous lesions in UC tissues. The level of REG IV mRNA expression was correlated with that of basic fibroblast growth factor (bFGF) as well as hepatocyte growth factor (HGF) mRNA expression in UC tissues. The REG IV gene expression in SW403 colon cancer cells was enhanced by stimulation with transforming growth factor- $\alpha$, epidermal growth factor, bFGF, and HGF. REG IV gene induction promoted cell growth and conferred resistance to $\mathrm{H}_{2} \mathrm{O}_{2}$-induced apoptosis in DLD-1 cells. The REG IV gene is inducible by growth factors and may function as a growth promoting and/or an antiapoptotic factor in the pathophysiology of UC.

Laboratory Investigation (2007) 87, 304-314. doi:10.1038/labinvest.3700507; published online 29 January 2007

KEYWORDS: cell growth; colitic cancer; growth factor; REG; ulcerative colitis

The pathogenesis of ulcerative colitis (UC) is still unclear, but dysregulated immune function appears to be involved in its chronic inflammatory process, resulting in continuous damage of the colonic mucosa. ${ }^{1-5}$ To regenerate the injured colonic tissues, growth factors are thought to play very important roles, and indeed, several growth factors are reported to be upregulated in the colonic tissues in UC. ${ }^{3,6,7}$ However, few comprehensive studies have examined the expression patterns of various growth factors in UC tissues simultaneously, and the network of and the relationships among growth factors in UC tissues are not fully understood.

Regenerating gene (REG) IV, the most recently discovered member of the REG gene family, was isolated from a cDNA library of UC tissues by Hartupee et al. ${ }^{8}$ Although the biological function of REG IV protein is still unclear, REG IV protein may play a role in cell growth because other REG family proteins have been shown to act as growth factors in gastrointestinal organs. ${ }^{9-14}$ However, it still remains unknown whether the REG IV gene is indeed involved in the pathophysiology of UC and whether REG IV protein really functions as a growth factor. Moreover, it has not been examined how REG IV gene expression is regulated. In the present study, therefore, in order to elucidate roles for $R E G$ $I V$ in the pathophysiology of UC, we investigated the relationship between REG IV gene expression and clinicopathological factors in patients with UC, and examined the mechanism of REG IV gene expression and the cell growth effect of REG IV protein in vitro. Furthermore, to clarify the relationship between the REG $I V$ gene and other growth factors in UC mucosa, we examined the expression of various growth factor genes together with that of REG IV.

\section{MATERIALS AND METHODS Tissue Specimens and Histological Examination}

Colon biopsy specimens were obtained by endoscopy from 22 patients with UC (13 men and nine women; mean age 44.7 years, range 19-79 years; mean disease duration 6.3 years, range $0-19$ years) and five normal controls (five men; age range 33-38 years) in 2003 and 2004 at Kyoto University

${ }^{1}$ Department of Gastroenterology and Hepatology, Kyoto University Graduate School of Medicine, Kyoto, Japan and ${ }^{2}$ Department of Surgical and Molecular Pathology, Dokkyo University School of Medicine, Tochigi, Japan

Correspondence: Dr H Fukui, MD, PhD, Department of Surgical and Molecular Pathology, Dokkyo University School of Medicine, 880, Kitakobayashi, Mibu, Shimotsuga, Tochigi 321-0293, Japan. E-mail: h-fukui@dokkyomed.ac.jp

Received 7 June 2006; revised 24 October 2006; accepted 29 October 2006 
Graduate School of Medicine. The tissue specimens were used for real time PCR and histological analyses.

A total of seven colitic cancer lesions (location: five rectum, one sigmoid, one descending; histology: four welldifferentiated adenocarcinomas, three mucinous adenocarcinomas) were obtained between 1997 and 2000 from specimens surgically resected from four patients (two men and two women; age range 44-58 years; disease duration 11-25 years) at Dokkyo University School of Medicine. The tissue specimens were fixed in $10 \%$ formalin solution, embedded in paraffin, and subjected to histological analyses.

This work was done with the approval of the Review Board of Kyoto University Hospital and the Dokkyo University Surgical Pathology Committee, and informed consent was obtained from all patients. The diagnosis of UC was based on established endoscopic and histologic criteria, ${ }^{15}$ and the degree of inflammation was evaluated according to Matts' grade $^{15}$ throughout the experiments.

\section{Real Time Reverse Transcription-Polymerase Chain Reaction}

Total RNA was isolated from colonic biopsy samples with Trizol reagent (Gibco BRL, Rockville, MD, USA). To generate cDNA, $5 \mu \mathrm{g}$ of total RNA was reverse-transcribed using $200 \mathrm{U}$ of SuperScript II reverse-transcriptase (Gibco BRL) and oligo-dT primer (Applied Biosystems, Branchburg, NJ, USA) in a total reaction volume of $20 \mu \mathrm{l}$ as described previously. ${ }^{16}$ TaqMan quantitative real time reverse transcription-polymerase chain reaction (RT-PCR) was performed with the ABI PRISM 7700 Sequence Detection System (Applied Biosystems, Foster City, CA, USA). The set of primers and probe for human REG IV, epidermal growth factor (EGF), transforming growth factor $(T G F)-\alpha$, basic fibroblast growth factor (bFGF), and hepatocyte growth factor (HGF) were prepared as shown in Table 1. In addition, a set of primers and probe for human glyceraldehyde-3-phosphate dehydrogenase (GAPDH) was synthesized by Applied Biosystems (Foster City, CA, USA).

Each amplification was done in $50 \mu$ l of reaction mixture with $50 \mathrm{ng}$ of cDNA, $250 \mathrm{nM}$ each growth factor probe (or $100 \mathrm{nM}$ GAPDH probe), $900 \mathrm{nM}$ each growth factor primer (or $200 \mathrm{nM}$ GAPDH primer), and $1 \times$ TaqMan universal PCR master mixture (Applied Biosystems, Branchburg, NJ, USA). The PCR cycling conditions were $50^{\circ} \mathrm{C}$ for $2 \mathrm{~min}, 95^{\circ} \mathrm{C}$ for $10 \mathrm{~min}$, followed by 45 cycles at $95^{\circ} \mathrm{C}$ for $15 \mathrm{~s}$ and $60^{\circ} \mathrm{C}$ for $60 \mathrm{~s}$. A template-free negative control was included in all amplifications, and each assay was performed in duplicate. The intensity of the dye fluorescence was determined, and the expression levels of growth factor mRNAs were normalized to GAPDH mRNA expression levels.

\section{In Situ Hybridization}

The 474-bp sequence of human REG IV was inserted into the pCRII vector using the TA cloning system (Invitrogen, Grand Island, NY, USA). To generate digoxigenin (DIG)-labeled sense and antisense RNA probes, the plasmid was linearized
Table 1 Primers and probes for REG IV and growth factors used in this study
Human REG IV
5'-TGCACGACCCACAGAAGAG-3' (sense)
5'-GACTTGCCAGACCAGGATCT-3' (antisense)
5'-FAM-AATCCACTGCCACTGCTG (probe)

Human EGF

5'-CCTGTAACACACATGCAGTGAGA-3' (sense)

5'-GGACTGACTTGGAAGGCACTT-3' (antisense)

5'-FAM-CTAGGGAGGCGTATAT (probe)

Human TGF- $\alpha$

5'-ACTGCACGTGCCCTGTAG-3' (sense)

5'-ACAGGAAACAAGTTGATGACATCGT-3' (antisense)

5'-FAM-ATCAGGAAGCAGAACAAA (probe)

Human bFGF

5'-CCGACGGCCGAGTTGA-3' (sense)

5'-CAACTCCTCTCTCTTCTGCTTGAA-3' (antisense)

5'-FAM-CCCTCACATCAAGCTAC (probe)

Human HGF

5'-CACCACACCGGCACAAATTC-3' (sense)
5'-GGGATTGCGGCAATAATTATCATCA-3' (antisense)
5'-FAM-TTGCCTGAAAGATATCC (probe)

with BamHI and NotI and transcribed, respectively, with T7 or SP6 RNA polymerase in the presence of DIG-UTP using the DIG-RNA labeling kit (Boehringer, Mannheim, Germany).

Tissue sections $(4 \mu \mathrm{m})$ were deparaffinized, rehydrated, treated with $18 \mu \mathrm{g} / \mathrm{ml}$ proteinase $\mathrm{K}$ at $37^{\circ} \mathrm{C}$ for $10 \mathrm{~min}$, postfixed in $4 \%$ paraformaldehyde, acetylated with acetic anhydride $(0.25 \% \mathrm{v} / \mathrm{v})$ in $0.1 \mathrm{~mol} / \mathrm{l}$ triethanolamine, and dehydrated in an ethanol series before hybridization. Hybridization was carried out in hybridization buffer containing DIGlabeled RNA probes $(1 \mu \mathrm{g} / \mathrm{ml})$ at $45^{\circ} \mathrm{C}$ overnight. After hybridization, the sections were treated with ribonuclease and washed in a solution of $2 \times$ standard saline citrate $/ 50 \%$ $(\mathrm{v} / \mathrm{v})$ deionized formamide at $55^{\circ} \mathrm{C}$ for $30 \mathrm{~min}$. Finally, the sections were reacted with anti-DIG antibody, and the signals were visualized with 4-nitroblue tetrazolium chloride and 5-bromo-4-chloro-3-indolyl phosphate (NBT/BCIP) (Roche, Mannheim, Germany).

\section{Immunohistochemistry}

Immunohistochemical staining for REG IV, chromogranin A and Ki67 was performed with an Envision Kit (DAKO, Kyoto, Japan) as described previously, ${ }^{16}$ using anti-human REG IV antibody (1:50; R\&D Systems, Minneapolis, MN, USA), anti-human chromogranin A antibody (ready to use; Immunotech, Marseille, France) and anti-human Ki67 antibody (1:50; DAKO, Kyoto, Japan). Finally, the sections were incubated in 3,3'-diaminobenzidine tetrahydrochloride with 
$0.05 \% \mathrm{H}_{2} \mathrm{O}_{2}$ for $5 \mathrm{~min}$ and then counterstained with Mayer's hematoxylin.

\section{Effects of Cytokines and Growth Factors on REG IV Gene Expression in Colon Cancer Cells}

The human colon cancer cell line SW403 was cultured in RPMI1640 medium (Invitrogen) with 10\% fetal bovine serum (Invitrogen) in a humidified incubator at $37^{\circ} \mathrm{C}$ with an atmosphere of $5 \% \mathrm{CO}_{2}$. The cells were seeded in $10-\mathrm{cm}$ dishes (Iwaki, Funabashi, Japan) and used for cytokine and growth factor stimulation tests when the cells reached subconfluence. The cells were stimulated with the indicated amount of TNF- $\alpha$ (Roche, Indianapolis, IN, USA), interleukin (IL)-6 (Roche), IL-8 (Roche), IFN- $\gamma$ (Roche), IL-1 $\beta$ (Roche), TGF- $\alpha$ (PeproTech Inc., Rocky Hill, NJ, USA), EGF (Roche), bFGF (Sigma, Saint Louis, MO, USA), and HGF (Sigma) in serum-free medium for $12 \mathrm{~h}$. Furthermore, in order to assess the inhibitory effect of MEK inhibitor on REG IV gene expression, the cells were pre-incubated with PD98059 (Sigma; 10 and $50 \mu \mathrm{M}$ ) for $1 \mathrm{~h}$, followed by additional incubation with or without bFGF or HGF for the indicated periods. After these treatments, the cells were subjected to Northern and Western blot analyses.

\section{RNA Preparation and Northern Blotting}

Total RNA was extracted from each cell line using Trizol reagent (Gibco BRL). Extracted RNA $(20 \mu \mathrm{g})$ from the colon cancer cell line was separated by electrophoresis in $0.66 \mathrm{M}$ formaldehyde $1 \%$ agarose gel. After transfer to a nitrocellulose membrane (Schleicher \& Schuell, Dassel, Germany), the nucleic acids were fixed to the membrane by UV cross-linking. The probes used for Northern blot analysis were a 0.47 -kilobase (kb) cDNA of human REG IV and a $0.63-\mathrm{kb}$ cDNA of human GAPDH. ${ }^{16}$ The radiolabeling of the probes, hybridization, and detection of signals were performed as described previously. ${ }^{10}$

\section{Western Blotting}

Cells were lysed in $20 \mathrm{mM}$ Tris- $\mathrm{HCl}$ buffer ( $\mathrm{pH}$ 7.4) containing $150 \mathrm{mM} \mathrm{NaCl}, 2 \mathrm{mM}$ EDTA, $1 \%$ Nonidet P-40, $50 \mathrm{mM} \mathrm{NaF}$, and $1 \times$ proteinase inhibitor (Complete Mini; Roche). Protein extract $(20 \mu \mathrm{g})$ was fractionated by sodium dodecyl sulfate-polyacrylamide gel electrophoresis and transferred to a polyvinylidene difluoride membrane. The membrane was incubated with anti-ERK and anti-phosphospecific ERK antibodies (Cell Signaling, Beverly, MA, USA) at $4^{\circ} \mathrm{C}$ over night, and then incubated with peroxidase-conjugated secondary anitibodies for $1 \mathrm{~h}$ at $37^{\circ} \mathrm{C}$. Proteins were detected by an enhanced chemiluminescence system (Amersham Pharmacia Biotech, Buckinghamshire, UK).

\section{Transfection and Expression of the Human REG IV CDNA} The full-length human REG IV cDNA with an EcoRI site at both the $5^{\prime}$ and $3^{\prime}$ ends was generated by reverse-transcription polymerase chain reaction from human stomach mRNA.
The fragment was once ligated in the pCRII vector and cloned. The cloned nucleotides were confirmed by sequencing, excised from the vector by cutting with EcoR I, and then inserted into the EcoR I restriction site in the pIRES2-EGFP vector containing the cytomegalovirus promoter driving the enhanced green fluorescent protein (EGFP) gene (Clontech, Palo Alto, CA, USA). After cloning and verifying the nucleotides of the human REG IV cDNA by sequencing, the construct was named pIRES2-hREG IV, and the pIRES2-EGFP vector without the insert was used as a control.

The plasmids were stably transfected into human colon cancer cell line DLD-1 using FuGENE6 transfection reagent (Roche) according to the manufacturer's protocol. To select cells with stable expression of pIRES2-hREG IV and pIRES2EGFP, the cells were cultured over 3-4 weeks in medium that contained G-418 (GIBCO; $1000 \mu \mathrm{g} / \mathrm{ml}$ ). Surviving colonies were pooled and maintained in the standard culture medium supplemented with G-418 $(1000 \mu \mathrm{g} / \mathrm{ml})$.

\section{BrdU Cell Proliferation Assay}

Cell proliferation was assessed by the BrdU Cell Proliferation Assay (Exalpha Biological Inc., Watertown, MA, USA). DLD1 cells $\left(1 \times 10^{4}\right)$, stably transfected with the pIRES2-hREG IV (DLD-1-REG IV cells) or pIRES2-EGFP (DLD-1-EGFP cells) vector, were plated in 96-well microplates (Iwaki) and incubated in serum-free DMEM for $24 \mathrm{~h}$. At $18 \mathrm{~h}$ prior to assessment, $20 \mu \mathrm{l}$ of 5-bromo-2'-deoxyuridine (BrdU) was added to each well according to the protocol supplied. The cells were fixed and the DNA was denatured using reagents supplied with the assay kit. The cells were incubated with anti-BrdU peroxidase conjugate, washed and incubated with color development substrate. The plates were read at $450 \mathrm{~nm}$ in a spectrophotometer (Molecular Devices Co., Sunnyvale, CA, USA).

\section{Cell Growth Assay}

Cell growth was assessed by a Cell Counting Kit-8 (Dojindo, Kumamoto, Japan), which consists of (2-methoxy-4-nitrophenyl)-3-(4-nitrophenyl)-5-(2,4-disulfophenyl)-2H-tetrazolium, monosodium salt: WST-8 and 1-methoxy-5methylphenazinium methylsulfate: 1-methoxy-PMS. DLD-1REG IV cells $\left(1 \times 10^{4}\right)$ and control DLD-1-EGFP cells were plated in 96-well microplates (Iwaki). The cells were incubated in serum-free DMEM for $48 \mathrm{~h}$. After addition of $10 \mu \mathrm{l}$ of the Cell Counting Kit-8 reagent and a 3-h incubation, the plates were read at $450 \mathrm{~nm}$ in a spectrophotometer (Molecular Devices Co.). In another experiment, the cells $\left(5 \times 10^{4}\right)$ were incubated in serum-free DMEM for 24 and $48 \mathrm{~h}$, followed by washing with PBS, and then harvested. The number of viable cells was counted with a Particle Counter Z1 system (Beckman Coulter, Hialeah, FL, USA).

\section{Caspase Assay}

Caspase activity was assessed using a Colorimetric CaspACE Assay System (Promega, Madison, WI, USA). DLD-1-REG 
IV $\left(1 \times 10^{6}\right)$ and control DLD-1-EGFP cells were cultured in $6-\mathrm{cm}$ culture dishes (Iwaki) and incubated in serum-free medium for $24 \mathrm{~h}$. The cells were then incubated for $2 \mathrm{~h}$ with different concentrations $(0-0.1 \mathrm{mmol} / \mathrm{l})$ of $\mathrm{H}_{2} \mathrm{O}_{2}$ in serumfree medium. Thereafter, the cells were incubated in serumfree medium for $24 \mathrm{~h}$ and resuspended in lysis buffer. Lysate $(50 \mu \mathrm{l})$ was reacted with Ac-DEVD-pNA in the 96-well microplate according to the manufacturer's protocol. For measurement of caspase-3 activity, the plates were read at $405 \mathrm{~nm}$ in a spectrophotometer (Molecular Devices Co.).

\section{TUNEL Assay}

DLD-1-REG IV cells $\left(2 \times 10^{4}\right)$ and control DLD-1-EGFP cells were cultured in 4-well culture slides (Falcon, Bedford, MA, USA). After $24 \mathrm{~h}$, the cells were incubated for $2 \mathrm{~h}$ with different concentrations $(0-5 \mathrm{mmol} / \mathrm{l})$ of $\mathrm{H}_{2} \mathrm{O}_{2}$ in serum-free medium. Thereafter, the cells were incubated in the routine medium for $24 \mathrm{~h}$. After washing with PBS, the slides were fixed with $10 \%$ buffered formalin for $15 \mathrm{~min}$ and then treated with $0.3 \% \mathrm{H}_{2} \mathrm{O}_{2}$ in methanol for $30 \mathrm{~min}$ at room temperature. The slides were then subjected to incubation with $0.1 \%$ TritonX-100 in $0.1 \%$ sodium citrate for $2 \mathrm{~min}$ on ice and stained using an In Situ Cell Death Detection Kit (Roche, Indianapolis, IN, USA) according to the supplied protocol. Briefly, the pretreated slides were incubated in TdT-mediated dUTP nick end-labeling (TUNEL) reaction mixture for $60 \mathrm{~min}$ at $37^{\circ} \mathrm{C}$. The slides were then washed in PBS, incubated with peroxidase-conjugated $\mathrm{Fab}$ fragments of antifluorescein at $37^{\circ} \mathrm{C}$ for $30 \mathrm{~min}$, washed in PBS, and visualized using 3,3'-diaminobenzidine tetrahydrochloride (DAB). One hundred cells were counted in five different visual fields (magnification, $\times 200$ ) on each section. TUNEL index was calculated as the percentage of positive cells.

\section{Cell Survival Assay}

DLD-1 cells $\left(4 \times 10^{4}\right)$, stably transfected with pIRES2-hREG IV (DLD-1-REG IV cells) or pIRES2-EGFP (DLD-1-EGFP) vectors, were plated in 12-well microplates (Iwaki). Thereafter, the cells were incubated for $2 \mathrm{~h}$ with different concentrations $(0-5 \mathrm{mmol} / \mathrm{l})$ of $\mathrm{H}_{2} \mathrm{O}_{2}$ in serum-free medium. Then, the cells were incubated in the routine medium for $24 \mathrm{~h}$, and the number of surviving cells was evaluated by trypan blue exclusion.

\section{Akt Phosphorylation}

To prepare conditioned medium, we cultured human embryonic kidney (HEK) $293 \mathrm{~T}$ cells in DMEM medium supplemented with $10 \%$ fetal bovine serum. In accordance with the manufacturer's protocol, cells were transfected with $10 \mu \mathrm{g}$ of pIRES2-hREG IV or control plasmid using Lipofectamine 2000 transfection reagent (Invitrogen). The medium was replaced by serum-free RPMI1640 medium after a 48 -h incubation period. The conditioned medium was then collected and stored frozen as a source of recombinant REG IV protein.
DLD-1 cells were cultured in $10-\mathrm{cm}$ dishes for $24 \mathrm{~h}$. After washing with PBS, the medium was changed to conditioned medium containing human recombinant REG IV or control medium, and the cells were incubated for another $12 \mathrm{~h}$. The cells were then mixed with lysis buffer as reported previously. ${ }^{9}$ Protein extract $(10 \mu \mathrm{g})$ was fractionated by sodium dodecyl sulfate polyacrylamide gel electropholesis, transferred to a polyvinylidene difluoride membrane, and Western blotting was performed using anti-Akt, antiphospho-specific Akt (Ser473) (New England Biolabs, Beverly, MA, USA), and anti- $\beta$-actin antibodies (Sigma Chemical Co., St Louis, MO, USA), as reported previously. ${ }^{9}$

\section{Statistical Analysis}

All values are expressed as the mean \pm s.e.m. Significance of differences between two groups was assessed by the unpaired two-tailed $t$ test, or by the Mann-Whitney $U$-test when data were not parametric. The relationships among REG IV and growth factor mRNA levels were assessed by linear regression analysis. A $P<0.05$ was considered to indicate statistical significance.

\section{RESULTS}

Detection of REG IV Gene Expression in Normal Colonic and Ulcerative Colitis Mucosa, and in Dysplasia and Colitic Cancer by In Situ Hybridization

In normal human colonic mucosa, REG IV mRNA was detected in only a few epithelial cells in the crypts (Figure 1a). On the other hand, in ulcerative colitis mucosa, the number of REG IV mRNA-positive epithelial cells was increased, and the signal intensity in each cell was enhanced (Figure 1b).

REG IV gene expression was detected in both dysplastic and cancerous cells in all seven samples of colitic cancer from the four patients examined, and the signal intensity was apparently stronger than that in normal colonic epithelial cells (Figure 1c and d). No signal was detected when using the DIG-labeled sense probe throughout the experiments (data not shown).

\section{Expression of REG IV Protein, Chromogranin A and Ki67 in Normal Colonic and Ulcerative Colitis Mucosa, and in Dysplasia and Colitic Cancer}

In normal colonic mucosa, REG IV and chromogranin A were co-expressed in a few epithelial cells in the basal portion of crypts (Figure 2a and b). However, some epithelial cells alternatively expressed REG IV or chromogranin A (Figure 2a and b). REG IV was also expressed in goblet cells at various intensities (Figure 2b). In UC mucosa, the number of REG IV-positive cells and chromogranin A-positive cells in the crypts was increased (Figure $2 \mathrm{~d}$ and e). Additionally, we found that REG IV-positive cells were mainly present in the lower part of the colonic mucosa (Figure 2e). REG IV protein was also strongly expressed in the most of the dysplastic and cancerous cells (Figure $2 \mathrm{~h}$ and $\mathrm{k}$ ), whereas chromogranin A was hardly expressed in these cells (Figure $2 \mathrm{~g}$ and $\mathrm{j}$ ). On the 

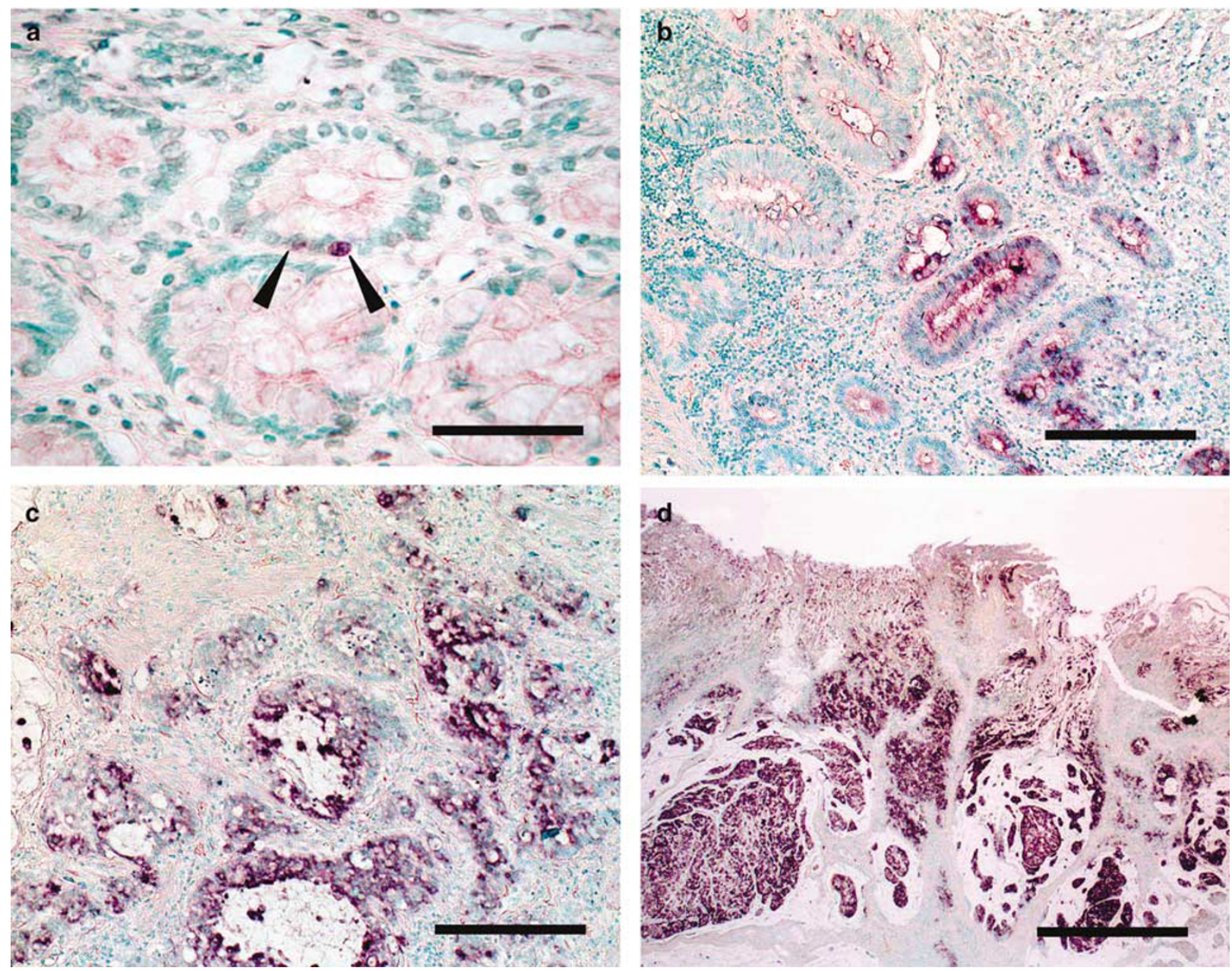

Figure 1 In situ hybridization of REG IV mRNAs in normal colon (a), UC (b), dysplasia (c), and colitic cancer (d) tissues. (a) Normal human colonic mucosa. Hybridized signals for REG IV mRNA (arrowheads) are evident in only a few epithelial cells in the crypts (bar $=50 \mu$ m). Inflamed (b) and dysplastic (c) epithelial cells in UC mucosa. Both the number of REG IV mRNA-positive cells and the signal intensity in each cell are markedly increased (bar $=100 \mu \mathrm{m}$ ). (d) Colitic cancer tissue. The nested cancer cells express very strong signals for REG IV mRNA (bar $=200 \mu \mathrm{m}$ ). (a-d) Tissue sections were visualized with NBT/BCIP and counter-stained with methyl green.

other hand, both the distribution and numerical change of Ki67-positive cells were relatively similar to those of REG IV-positive cells in normal, inflamed, dysplastic and cancerous tissues (Figure 2c, f, i, and l).

\section{Expression of REG IV and Growth Factor mRNAs in Normal Colonic and Ulcerative Colitis Mucosa}

REG IV mRNA expression was detectable by real-time PCR in all samples of colonic mucosa from both control and UC patients. As shown in Figure 3a, the level of REG IV mRNA expression was significantly greater in UC tissues than in normal colonic tissues $(P<0.05)$. In addition, the levels of $b F G F$ and $H G F$ mRNA expression were significantly greater in UC tissues than in normal colonic tissues $(P<0.05)$, and the TGF- $\alpha$ mRNA expression level tended to be increased in UC tissues. We then analyzed the relationship between the severity of inflammation and REG IV or growth factor mRNA expression (Figure $3 \mathrm{~b}$ ). In the Matts 1, 2 score group, none of the genes examined showed a difference in expression level from those in the control group, although the REG IV and HGF mRNA expression levels in the Matts 1, 2 score group tended to be higher in UC tissues than in normal colonic tissues. In the Matts 3, 4, 5 score group, REG IV, bFGF and, HGF mRNA expression levels were significantly increased $(P<0.05$ vs control). Although there was no significant difference, the TGF- $\alpha$ mRNA expression level in the Matts 3, 4, 5 score group tended to be higher in UC tissues than in normal colonic tissues. On the other hand, in none of the genes examined was there any significant relationship between expression level and age, sex, or disease duration (data not shown).

Furthermore, we analyzed the correlation between REG IV and growth factor expression in UC tissues. The expression level of REG IV was correlated significantly with that of $b F G F$ $(P<0.05)$ and HGF $(P<0.05)$ but not with that of $E G F$ or TGF- $\alpha$ in UC tissues (Figure $3 \mathrm{c}$ and $\mathrm{d}$ ). 


\section{Chromogranin A}

\section{Normal colon}
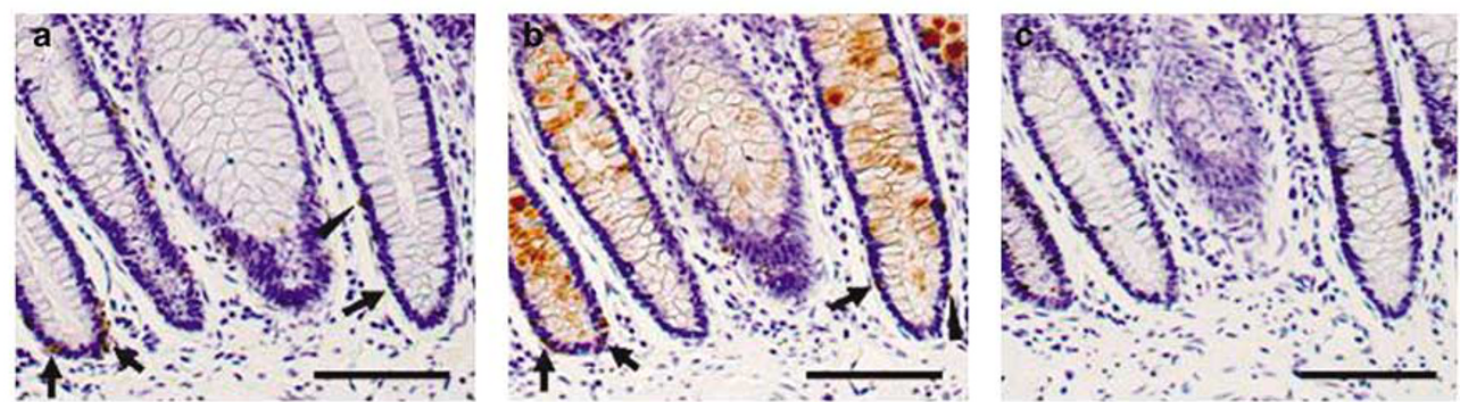

\section{UC mucosa}
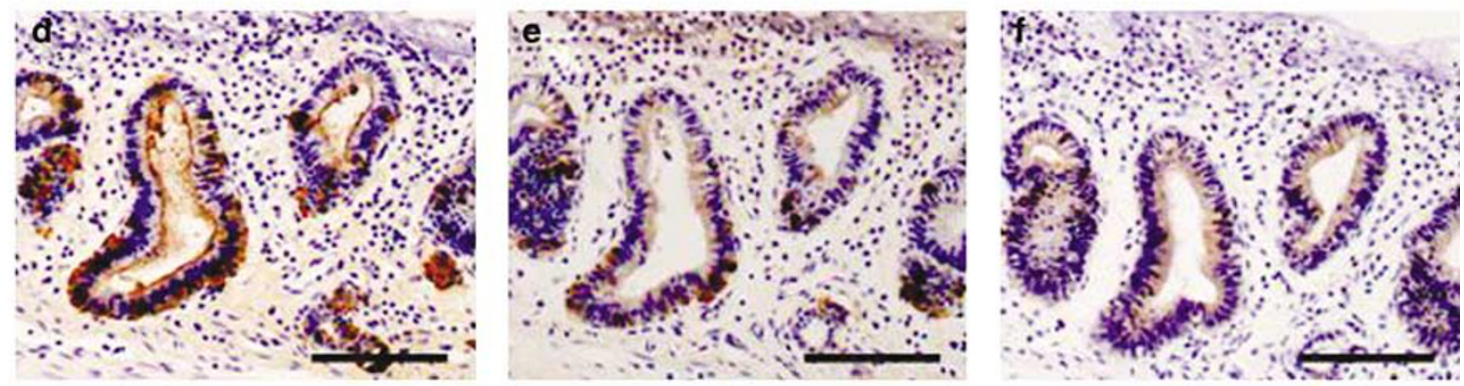

\section{Dysplasia}
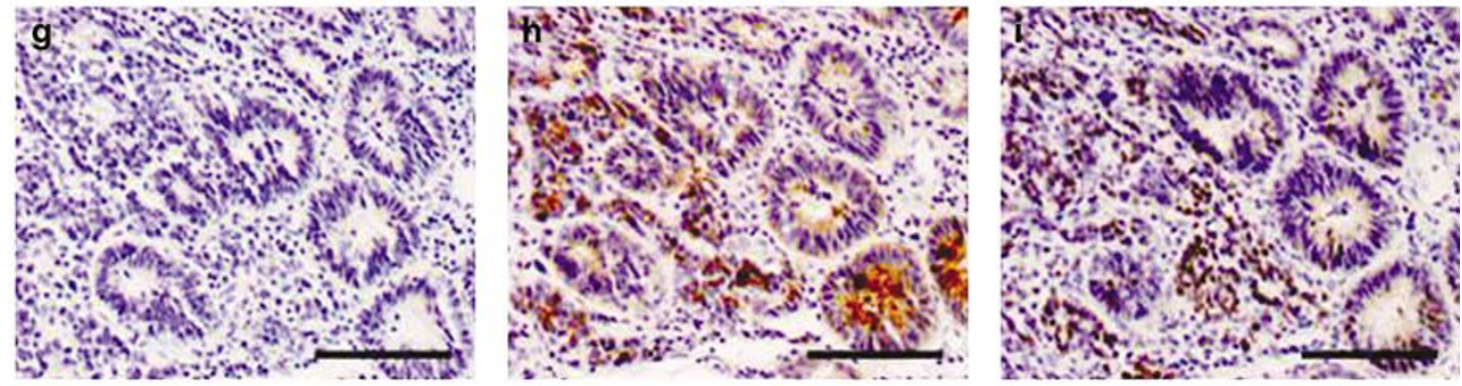

\section{Colitic cancer}
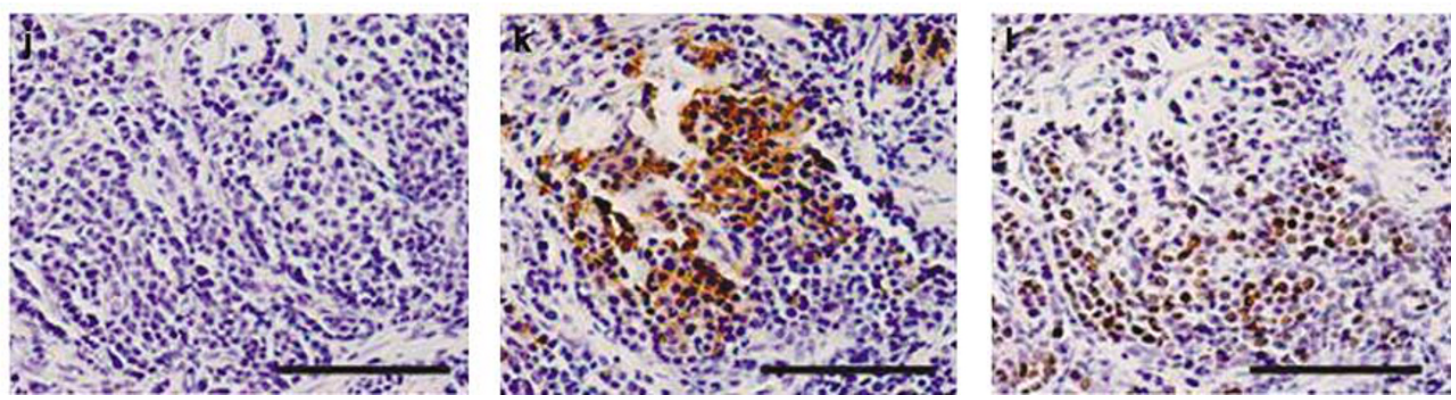

Figure 2 Serial immunostainings of REG IV protein, chromogranin A and Ki67 in normal colonic (a-c) and UC mucosa (d-f), and in dysplasia (g-i) and colitic cancer (j-I). In normal colonic mucosa, REG IV and chromognanin A were co-expressed in a few epithelial cells in the basal portion of crypts (a, $\mathbf{b}$, arrows). However, some epithelial cells alternatively expressed REG IV or chromogranin A (a, b, arrows heads). In UC mucosa, the number of chromogranin A-positive cells (d) and REG IV-positive cells (e) in the crypts was increased. REG IV protein was also strongly expressed in the most of the dysplastic (h) and cancerous cells $(\mathbf{k})$, whereas chromogranin A was hardly expressed in these cells $(\mathbf{g}$, j). Both the distribution and numerical change of Ki67-positive cells were relatively similar to those of REG IV-positive cells in normal (c), inflamed (f), dysplastic (i) and cancerous tissues (I). Bars $=100 \mu \mathrm{m}$. 

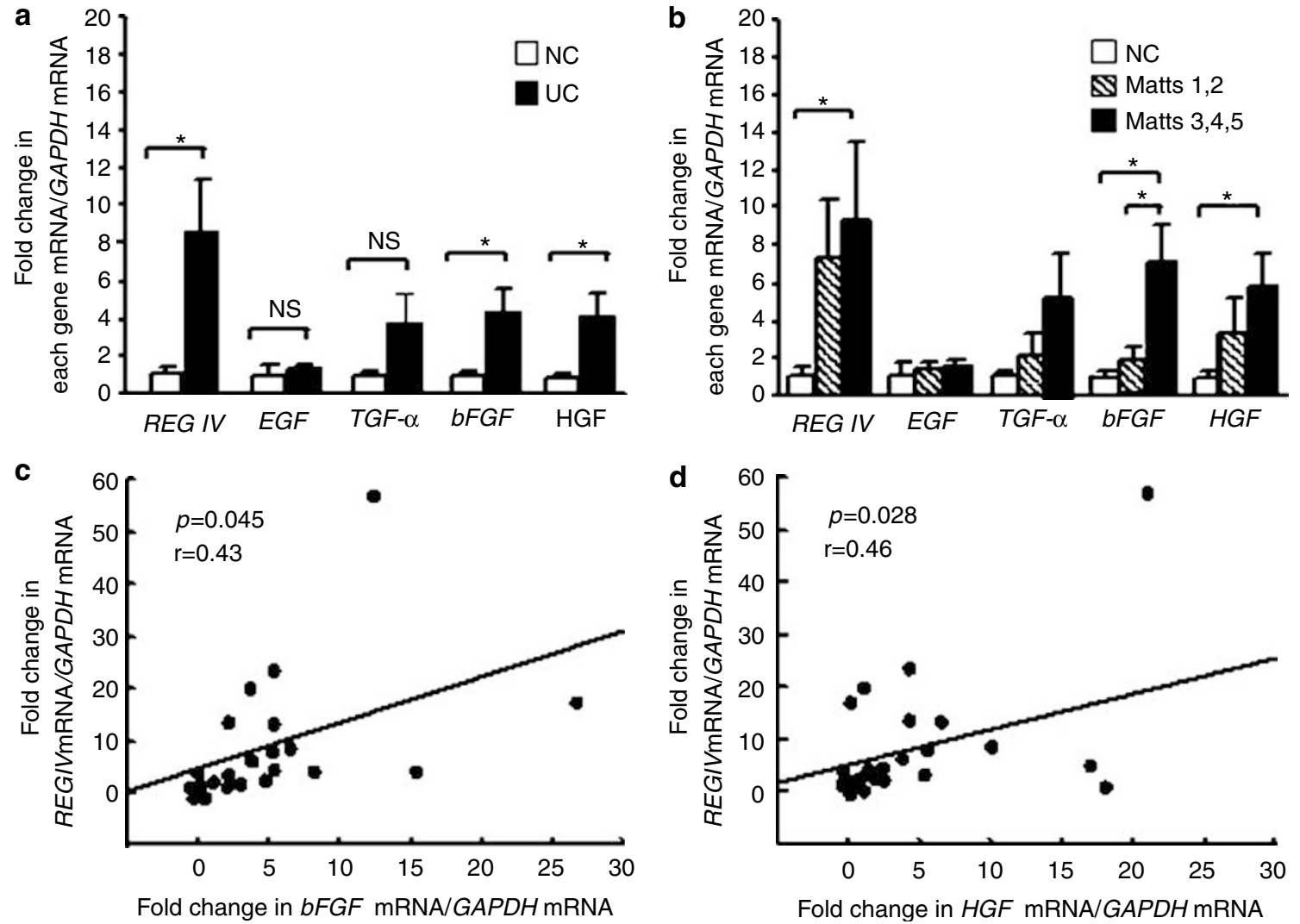

Figure 3 REG IV mRNA expression in UC tissues. (a) Expression levels of mRNA for REG IV and other growth factors in normal colon and UC tissues. (b) Comparison of mRNA expression levels for REG IV and other growth factors among UC groups subdivided by histological findings. Correlation between REG $I V$ and $b F G F$ (c) or HGF (d) gene expression levels in UC tissues. All results are expressed as fold change in REG IV, bFGF, and HGF mRNA/GAPDH mRNA ratio relative to the normal control group. Significantly different between two groups: ${ }^{\star} P<0.05$. NS; not significant.

Effects of Cytokines and Growth Factors on REG IV Gene Expression in Colon Cancer Cell Line SW403

None of TNF- $\alpha$ (500 and $1000 \mathrm{IU} / \mathrm{ml})$, IL-6 (100 and $1000 \mathrm{IU} / \mathrm{ml}), \mathrm{IL}-8$ ( 1 and $10 \mathrm{ng} / \mathrm{ml}), \mathrm{IFN}-\gamma$ (100 and $500 \mathrm{IU} /$ $\mathrm{ml}$ ) or IL-1 $\beta$ (50 and $500 \mathrm{IU} / \mathrm{ml}$ ) had any significant effect on REG IV gene expression in human colon cancer cell line SW403 (Figure 4). In contrast, treatment with TGF- $\alpha$ ( 1 and $10 \mathrm{nM})$, EGF (10 and $100 \mathrm{nM})$, bFGF ( 1 and $10 \mathrm{nM}$ ) or HGF $(0.1$ and $1 \mathrm{nM})$ significantly enhanced REG IV mRNA expression in this cell line. Similar results were also obtained from the $\mathrm{CaCO}_{2}$ colon cancer cell line (data not shown).

\section{Effects of bFGF and HGF on REG IV Gene Expression in Colon Cancer Cell Line SW403}

As mentioned above, treatment with bFGF $(10 \mathrm{nM})$ or HGF $(1 \mathrm{nM})$ significantly enhanced $R E G I V$ mRNA expression in SW403 cells. The increase of REG IV mRNA expression by bFGF as well as by HGF was associated with a significant enhancement of ERK phosphorylation (Figure $5 \mathrm{a}$ and $\mathrm{b}$ ). The enhanced phosphorylation of ERK by bFGF $(10 \mathrm{nM})$ as well as by HGF ( $1 \mathrm{nM})$ was suppressed by concomitant administration of the MAPK kinase inhibitor PD98059 (10 and $50 \mu \mathrm{M}$ ) (Figure 5b), and the decreases of ERK phosphoryla- tion by PD98059 were accompanied by a reduction of $R E G$ $I V$ mRNA expression (Figure $5 \mathrm{a}$ and $\mathrm{b}$ ).

\section{Effects of REG IV Gene Induction on BrdU Incorporation and Cell Growth in DLD-1 Cells}

DLD-1 cells transfected with pIRES2-hREG IV (DLD-1-REG IV) showed significantly higher BrdU incorporation than did DLD-1 cells transfected with pIRES2-EGFP (DLD-1-EGFP; control) $(P<0.01)$ (Figure 6a). Moreover, DLD-1-REG IV cells showed significantly higher WST-8 cleavage levels than did DLD-1-EGFP cells $(P<0.01)$ (Figure 6b), suggesting that $R E G I V$ gene induction enhances the growth activity of DLD1 cells. Compatible with these results, REG IV gene induction in DLD-1 cells significantly promoted numerical cell growth at 24 and $48 \mathrm{~h}$ of culture time (Figure $6 \mathrm{c}$ ). Similar results were obtained using the HT29 colon cancer cell line (data not shown).

\section{Effects of REG IV Gene Induction on Apoptosis and Survival of DLD-1 Cells}

We examined both specific caspase- 3 activity and TUNEL positivity to compare the apoptotic effects of $\mathrm{H}_{2} \mathrm{O}_{2}$ treatment on DLD-1 cells transfected with the pIRES2-hREG IV and 
pIRES2-EGFP (control) plasmids. As shown in Figure 7a, the caspase activity of DLD-1-REG IV cells in response to $\mathrm{H}_{2} \mathrm{O}_{2}$ (0.03 and $0.1 \mathrm{mM})$ was significantly lower than that of DLD1-EGFP cells. In addition, the DLD-1-REG IV cells showed significantly lower TUNEL positivity than the DLD-1-EGFP cells when they were treated with $\mathrm{H}_{2} \mathrm{O}_{2}$ at concentrations

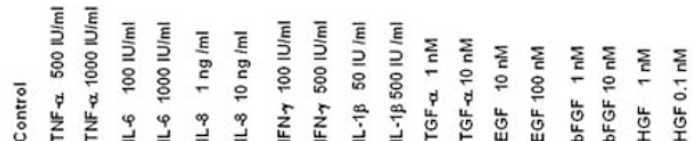

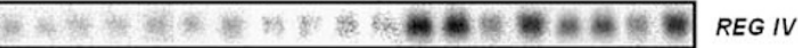

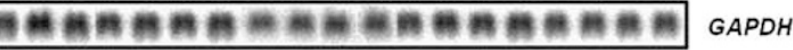

Figure 4 Effects of various cytokines and growth factors on REG IV mRNA expression in SW403 cells. Total RNA ( $20 \mu \mathrm{g}$ ) was extracted $12 \mathrm{~h}$ after stimulation with cytokines or growth factors and analyzed by Northern blotting using ${ }^{32}$ P-labeled cDNAs for REG IV and GAPDH mRNA. of 1-5 mM, suggesting that REG IV-overexpressing cells are more resistant to apoptosis induced by $\mathrm{H}_{2} \mathrm{O}_{2}$ (Figure $7 \mathrm{~b}$ ). Consistent with these data, the DLD-1-REG IV cells showed a significantly higher survival rate than the DLD-1-EGFP cells upon exposure to $\mathrm{H}_{2} \mathrm{O}_{2}$ (1-5 mM) (Figure 7c).

We then examined the alteration of intracellular signaling by REG IV protein, and found that treatment with REG IV conditioned medium enhanced the phosphorylation of Akt in DLD-1 cells (Figure 7e).

\section{DISCUSSION}

$R E G I V$, a newly characterized member of the regenerating gene family, was isolated from a cDNA library of UC tissues, ${ }^{8}$ implying that the REG IV gene plays some roles in the pathophysiology of UC. In the present study, we demonstrated histologically that in the normal crypt base REG IV protein is expressed in a few epithelial cells showing neuroendocrine features. This finding, which is similar to that for REG I $\alpha$ protein in colon tissues, ${ }^{12}$ is compatible with the observation

a

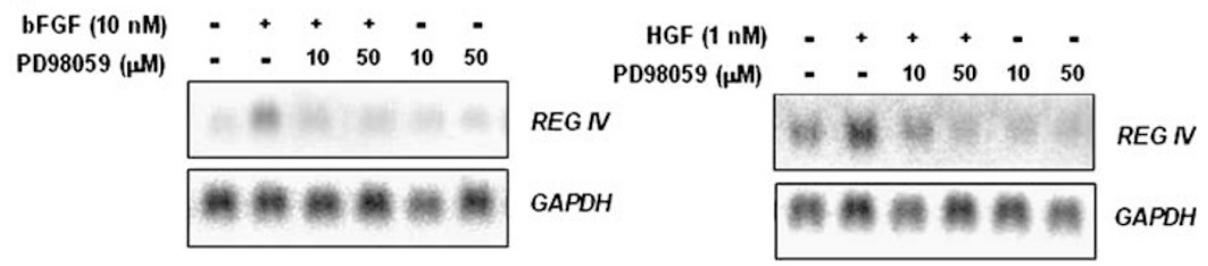

b
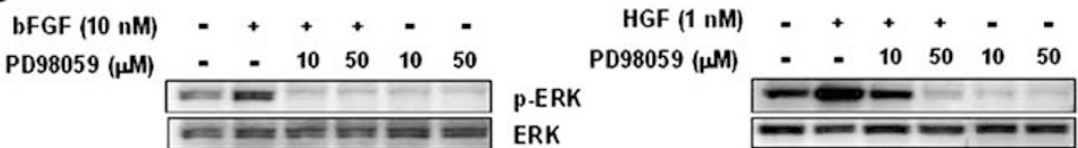

p.ERK

ERK

Figure 5 Effects of bFGF and HGF on REG IV gene expression via the MAPK pathway in SW403 cells. (a) The cells were preincubated with 10 or $50 \mu$ M PD98059 for $1 \mathrm{~h}$ and stimulated with $10 \mathrm{nM}$ bFGF or $1 \mathrm{nM} \mathrm{HGF}$ for $12 \mathrm{~h}$. Total RNA (20 $\mu \mathrm{g})$ was extracted and analyzed by Northern blotting using ${ }^{32} \mathrm{P}$-labeled cDNAs for REG IV and GAPDH mRNA. (b) The cells were preincubated with 10 or $50 \mu \mathrm{M}$ PD98059 for $1 \mathrm{~h}$ and stimulated with $10 \mathrm{nM}$ bFGF or $1 \mathrm{nM}$ HGF for $15 \mathrm{~min}$. Cell lysates were prepared and subjected to immunoblot analysis with anti-ERK and anti-phospho-specific ERK antibodies.
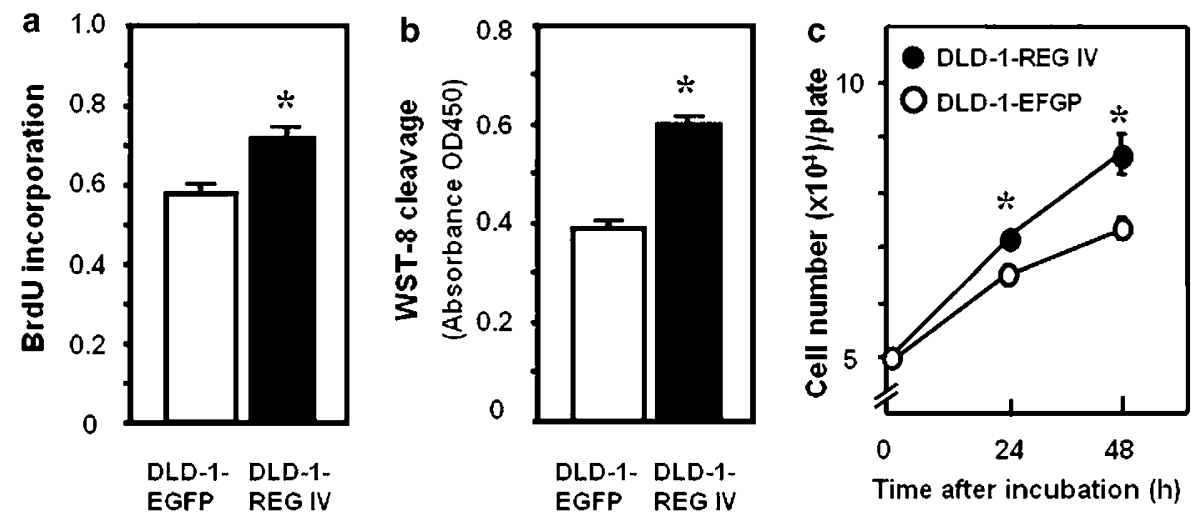

Figure 6 Effects of REG IV gene induction on BrdU incorporation by (a) and growth of (b, c) human colon cancer cells. DLD-1 cells transfected with pIRES2hREG IV (DLD-1-REG IV) or pIRES2-EGFP (DLD-1-EGFP; control) plasmids were used for both BrdU incorporation and cell growth assays as described in Materials and methods. All results are expressed as the mean \pm s.e.m. of eight samples. ${ }^{\star} P<0.01$ vs control (DLD-1-EGFP cells) group. 

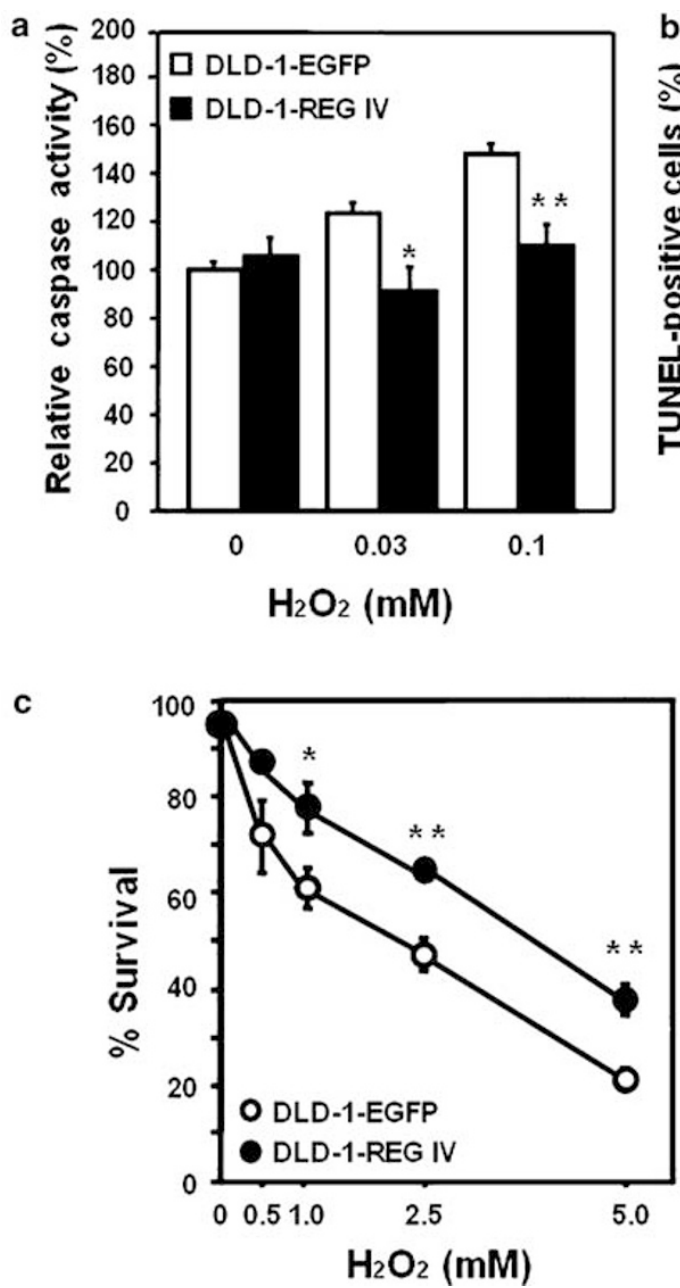
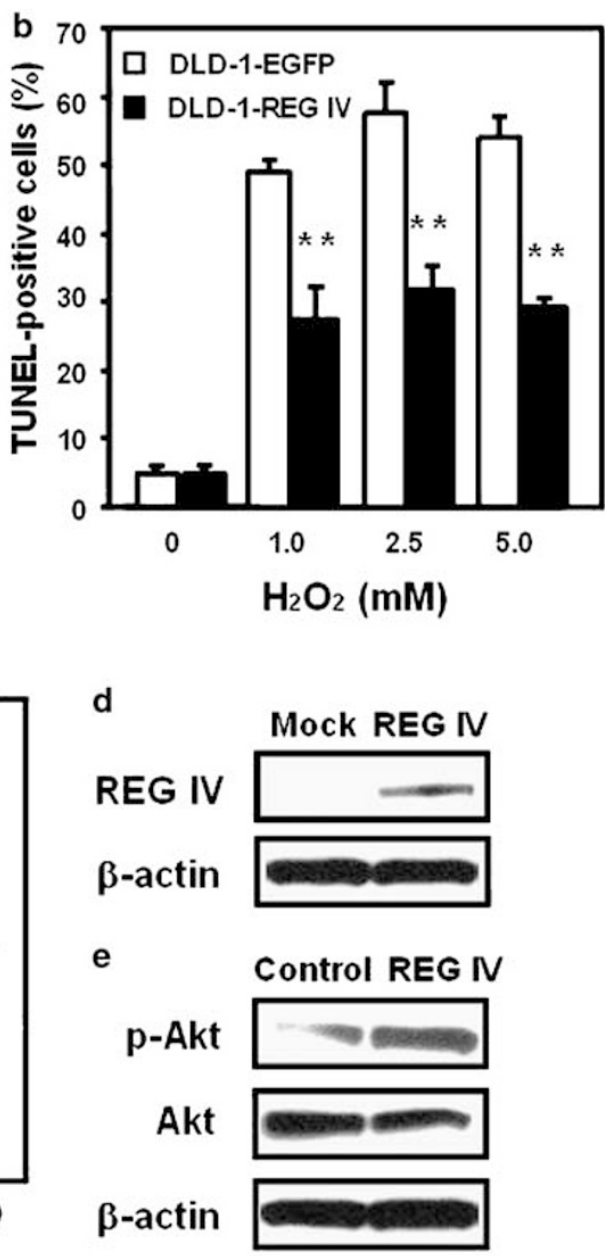

Figure 7 Effects of REG IV gene induction on $\mathrm{H}_{2} \mathrm{O}_{2}$-induced apoptosis and cell death of human colon cancer cells. DLD-1 cells transfected with pIRES2-hREG IV (DLD-1-REG IV) or pIRES2-EGFP (DLD-1-EGFP; control) plasmids were treated with different concentration of $\mathrm{H} 2 \mathrm{O} 2 \mathrm{for} 2 \mathrm{~h}$ and assessed for caspase activity (a), TUNEL positivity (b), and cell survival (c) as described in Materials and methods. (d) Source of REG IV protein. Human embryonic kidney HEK293T cells were transfected with a human REG IV cDNA expression plasmid or a control plasmid, and the medium conditioned by these cells was collected. Release of REG IV protein (approximately $17 \mathrm{kDa}$ ) into the conditioned medium was confirmed by Western blot analysis with an anti-human REG IV polyclonal antibody. (e) Effect of REG IV conditioned medium on phosphorylation of Akt. All results are expressed as the mean \pm s.e.m. of four samples. ${ }^{\star} P<0.05$, ${ }^{*} P<0.01$ vs control (DLD-1-EGFP cells) group at the same dose point.

by Kämäräinen ${ }^{17}$ and Oue et $a l,{ }^{18}$ and suggests functional roles for REG IV protein in normal colonic mucosa. However, in UC tissues REG IV expression is abundantly enhanced, and the distributions of positivity for REG IV and chromogranin A were apparently distinct. Although we cannot explain this discrepancy, it is temping to speculate that a proportion of REG IV-positive cells may originate from non-endocrine cells in the UC mucosa. On the other hand, the distribution of REG IV-positive cells is relatively similar to that of Ki67-positive cells, suggesting that REG IV expression may be associated with proliferative behavior of epithelial cells in the UC mucosa. Interestingly, by using gene-chip analysis, several investigators have recently reported that a number of REG family proteins are markedly upregulated in the colonic mucosa of patients with UC. ${ }^{19,20}$ Indeed, we have also shown enhancement of REG I $\alpha$ gene expression in the colonic tissue of UC patients. ${ }^{12}$ Moreover, others have reported an increase of REG III gene expression in UC mucosa. ${ }^{21,22}$ Thus, our present study showing that the $R E G I V$ gene is also upregulated in the UC colonic mucosa strongly suggests generalized upregulation of $R E G$ family genes in the colonic mucosa of UC patients.

In addition to REG IV gene expression, we found in this study that the expression of both $b F G F$ and $H G F$ mRNA was significantly enhanced, and moreover that TGF- $\alpha$ mRNA expression tended to be increased in UC tissues. Thus, in addition to REG family proteins including REG IV, many growth factors appear to be involved in repair of the injured mucosa of patients with UC. Then, it may be interesting to ask why these various growth factors are concurrently upregulated in UC tissues. In this regard, we found in the present study that the level of REG IV expression showed significant 
positive correlations with those of $b F G F$ and $H G F$, although the REG IV gene is expressed in colonic epithelial cells while bFGF and HGF are produced mainly by interstitial mesenchymal cells. ${ }^{23-26}$ These findings may indicate the presence of mutual interaction between growth factors in the epithelium and those in the interstitial cells.

In previous studies, we and others have demonstrated that the REG I $\alpha$ gene is involved in inflammatory diseases ${ }^{27,28}$ and that its expression is enhanced by proinflammatory cytokines such as IFN- $\gamma$ and IL-6. ${ }^{9,12,29-31}$ On the other hand, others have also demonstrated enhancement of REG III gene expression by several cytokines. ${ }^{32,33}$ Accordingly, we also examined whether REG IV gene expression is stimulated by various proinflammatory cytokines. However, in contrast to REG I $\alpha$ or REG III expression, we found that none of TNF- $\alpha$, IL-6, IL-8, IFN- $\gamma$, or IL- $1 \beta$ had any stimulatory effect on $R E G$ $I V$ gene expression in the human colon cancer cell line SW403. Therefore, we next examined the effects of various growth factors on REG IV expression because, as mentioned above, we had observed that the expression of not only REG $I V$ but also that of various growth factor genes was upregulated, and that REG IV expression was positively correlated with $b F G F$ and $H G F$ expression in the colonic mucosa of UC patients. Interestingly, we found that stimulation with not only bFGF and HGF but also EGF and TGF- $\alpha$, clearly enhanced the expression of REG IV mRNA in SW403 colon cancer cells. These growth factors are known to utilize the MAPK signaling cascade as their common signaling pathway. Indeed, we have shown in this study that the increase of REG $I V$ gene expression by bFGF and HGF was dependent on activation of the MAPK pathway. Thus, since we found a positive correlation between expression of the REG IV gene and that of the $b F G F$ and $H G F$ genes in the UC colonic mucosa, it appears likely that the enhanced expression of the REG IV gene is at least partly due to upregulation of bFGF and HGF in the mesenchymal cells. On the other hand, since the expression of the EGF receptor or other growth factor receptors may be upregulated in UC tissues, ${ }^{3,6}$ not only growth factors but also their receptors are likely responsible for REG IV expression. In this context, as described above, we previously reported that cytokines such as IFN- $\gamma$ and IL-6 are responsible for the enhanced expression of REG I $\alpha$ in the UC colonic mucosa. ${ }^{12}$ Thus, it is tempting to hypothesize that expression of the REG I $\alpha$ and REG IV genes is regulated specifically by different molecules, cytokines and growth factors. Interestingly, Bishnupuri et $a l^{34}$ recently reported that REG IV protein activates the EGF receptor/Akt/AP-1 signaling pathway in human colon cancer cell lines. Thus, because EGF and TGF- $\alpha$ enhanced REG IV gene expression in this study, it is tempting to hypothesize that a positive functional loop exists between EGF/TGF- $\alpha$ and REG IV protein.

In this study, although we examined only four patients with colitic cancer, our data clearly revealed that REG IV is overexpressed not only in the dysplastic epithelial cells but also in colitic cancer cells of UC patients, suggesting the importance of REG IV in the development of colitic cancer from UC mucosa. In this regard, we demonstrated that REG $I V$-overexpressing colon cancer cells gain significant growth ability. Thus, similar to REG I $\alpha$ protein, REG IV may also be involved in the development of colitic cancer through its growth-promoting action, although it still remains to be elucidated whether REG IV protein acts as a trophic factor on normal colonic epithelial cells. REG family proteins are known to have a similar structure to C-type lectins that possess various biological functions, including cell recognition, cell migration, cell growth and cell adhesion. ${ }^{35,36}$ Therefore, in addition to its growth-promoting action, REG IV together with other REG family proteins may be involved in the development of colitic cancer by exerting a variety of actions. Indeed, similar to REG I $\alpha$, we have shown that REG IV protein has not only a mitogenic but also an antiapoptotic effect on colon cancer cells and exerts its effects at least in part by activation of Akt signaling. Thus REG family proteins may commonly act as mitogenic and/or antiapoptotic factors in the development of colitic cancer although their regulatory effects on gene expression may differ.

In summary, we have shown that the REG IV gene is expressed in not only epithelial cells of the UC mucosa but also dysplastic epithelial cells and colitic cancer cells. The expression of REG IV and other growth factor genes was concurrently enhanced, and REG IV expression was positively correlated with $b F G F$ and $H G F$ expression in UC mucosa. In vitro studies demonstrated that REG IV gene expression was enhanced by bFGF and HGF via the MAPK-dependent pathway. Moreover, REG IV-overexpressing colon cancer cells gained significant growth ability. Taken together, these results suggest that REG IV and other growth factors may act cooperatively to promote epithelial cell growth in the UC-colitic cancer sequence.

\section{ACKNOWLEDGEMENT}

Grant Support: This work was supported by Grants-in-aid for Scientific Research 17590635, 16017240, 15209024, and 15659169 from the Ministry of Education, Culture, Sports, Science and Technology of Japan, and Grantsin-aid for Research on Measures for Intractable Diseases, and Research on Advanced Medical Technology from the Ministry of Health, Labor, and Welfare, Japan.

1. Panés J. Inflammatory bowel disease: pathogenesis and targets for therapeutic interventions. Acta Physiol Scand 2001;173:159-165.

2. Fiocchi C. Inflammatory bowel disease: etiology and pathogenesis. Gastroenterology 1998;115:182-205.

3. Beck PL, Podolsky DK. Growth factors in inflammatory bowel disease. Inflamm Bowel Dis 1999;5:44-60.

4. Nagura $\mathrm{H}$, Ohtani $\mathrm{H}$, Sasano $\mathrm{H}$, et al. The immuno-inflammatory mechanism for tissue injury in inflammatory bowel disease and Helicobacter pylori-infected chronic active gastritis. Digestion 2001:63:12-21.

5. Autschbach F, Giese T, Gassler N, et al. Cytokine/chemokine messenger-RNA expression profiles in ulcerative colitis and Crohn's disease. Virchows Arch 2002;441:500-513.

6. Chowdhury A, Fukuda R, Fukuoto S. Growth factor mRNA expression in normal colorectal mucosa and in uninvolved mucosa from ulcerative colitis patients. J Gastroenterol 1996;31:353-360. 
7. Babyatsky MW, Rossiter G, Podlsky DK. Expression of transforming growth factors $\alpha$ and $\beta$ in colonic mucosa in inflammatory bowel disease. Gastroenterology 1996;110:975-984.

8. Hartupee JC, Zhang $\mathrm{H}$, Bonaldo MF, et al. Isolation and characterization of a CDNA encoding a novel member of the human regenerating protein family: Reg IV. Biochim Biophys Acta 2001;1518:287-293.

9. Sekikawa $A$, Fukui $H$, Fujii $S$, et al. REG $1 \alpha$ protein may function as a trophic and/or anti-apoptotic factor in the development of gastric cancer. Gastroenterology 2005;128:642-653.

10. Fukui $\mathrm{H}$, Kinoshita $\mathrm{Y}, \mathrm{Maekawa} \mathrm{T}$, et al. Regenerating gene protein may mediate gastric mucosal proliferation induced by hypergastrinemia in rats. Gastroenterology 1998;115:1483-1493.

11. Watanabe $\mathrm{T}$, Yonemura $\mathrm{Y}$, Yonekura $\mathrm{H}$, et al. Pancreatic beta-cell replication and amelioration of surgical diabetes by Reg production. Proc Natl Acad Sci USA 1994;91:3589-3592.

12. Sekikawa $A$, Fukui $H$, Fujii $S$, et al. Possible role of REG $1 \alpha$ protein in ulcerative colitis and colitic cancer. Gut 2005;54:1437-1444.

13. Levine $\mathrm{JL}$, Patel $\mathrm{KJ}$, Zheng $\mathrm{Q}$, et al. A recombinant rat regenerating protein is mitogenic to pancreatic derived cells. J Surg Res 2000;89: 60-65.

14. Simon MT, Pauloin A, Normand G, et al. HIP/PAP stimulates liver regeneration after partial hepatectomy and combines mitogenic and anti-apoptotic functions through the PKA signaling pathway. FASEB J 2003;17:1441-1450.

15. Matts SG. The value of rectal biopsy in the diagnosis of ulcerative colitis. Quart J Med 1961;120:393-407.

16. Fukui $\mathrm{H}$, Fujii S, Takeda J, et al. Expression of Reg $\mathrm{l} \alpha$ protein in human gastric cancers. Digestion 2004;69:177-184.

17. Kämäräinen $M$, Heiskala $K$, Knuutila $S$, et al. RELP, a novel human Reg-like protein with up-regulated expression in inflammatory and metaplastic gastrointestinal mucosa. Am J Pathol 2003;163. $11-20$.

18. Oue N, Mitani Y, Aung PP, et al. Expression of localization of Reg IV in human neoplastic and non-neoplastic tissues: Reg IV expression is associated with intestinal and neuroendocrine differentiation in gastric adenocarcinoma. J Pathol 2005;207:185-198.

19. Lawrance IC, Fiocchi C, Chakravarti S. Ulcerative colitis and Crohn's disease: distinctive gene expression profiles and novel susceptibility candidate genes. Hum Mol Genet 2001;10:445-456.

20. Dieckgraefe BK, Stenson WF, Korzenik JR, et al. Analysis of mucosal gene expression in inflammatory bowel disease by parallel oligonucleotide arrays. Physiol Genomics 2000;4:1-11.

21. Ogawa $H$, Fukushima $K$, Naito $H$, et al. Increased expression of HIP/PAP and Regenerating gene III in human inflammatory bowel disease and a murine bacterial reconstitution model. Inflamm Bowel Dis 2003;9:162-170
22. Gironella M, lovanna JL, Sans $M$, et al. Anti-inflammatory effects of pancreatitis associated protein in inflammatory bowel disease. Gut 2005;54:1244-1253.

23. Cordon-Cardo C, Vlodavsky I, Haimovitz-Friedman A, et al. Expression of basic fibroblast growth factor in normal human tissues. Lab Invest 1990;63:832-840.

24. Galzie Z, Kinsella AR, Smith JA. Fibroblast growth factors and their receptors. Biochem Cell Biol 1997;75:669-685.

25. Goke $M$, Kanai $M$, Podolsky DK. Intestinal fibroblasts regulate intestinal epithelial cell proliferation via hepatocyte growth factor. Am J Physiol 1998;274:G809-G818.

26. Matsumoto $\mathrm{K}$, Tajima $\mathrm{H}$, Hananoue $\mathrm{M}$, et al. Identification and characterization of injurin, an inducer of expression of the gene for hepatocyte growth factor. Proc Natl Acad Sci USA 1992;89:3800-3804.

27. Fukui H, Franceschi F, Penland RL, et al. Effects of Helicobacter pylori infection on the link between regenerating gene expression and serum gastrin levels in Mongolian gerbils. Lab Invest 2003;83:1777-1786.

28. Graf R, Schiesser M, Lüssi A, et al. Coordinate regulation of secretory stress proteins (PSP/reg, PAP I, PAP II, and PAP III) in the rat exocrine pancreas during experimental acute pancreatitis. J Surg Res 2002;105:136-144.

29. Akiyama T, Takasawa $S$, Nata $K$, et al. Activation of Reg gene, a gene for insulin-producing $\beta$-cell regeneration: Poly(ADP-ribose) polymerase binds Reg promoter and regulates the transcription by autopoly(ADPribosyl)lation. Proc Natl Acad Sci USA 2001;98:48-53.

30. Dusetti NJ, Mallo GV, Ortiz EM, et al. Induction of lithostathine/reg mRNA expression by serum from rats with acute pancreatitis and cytokines in pancreatic acinar AR-42J cells. Arch Biochem Biophys 1996;330:129-132.

31. Judd LM, Alderman BM, Howlett M, et al. Gastric cancer development in mice lacking the SHP2 binding site on the IL-6 family co-receptor gp130. Gastroenterology 2004;126:196-207.

32. Rechreche $\mathrm{H}$, Montalto $\mathrm{G}$, Mallo GV, et al. pap, reg $\mathrm{l} \alpha$ and reg $\mathrm{I} \beta$ mRNAs are concomitantly up-regulated during human colorectal carcinogenesis. Int J Cancer 1999;81:688-694.

33. Dusetti NJ, Ortiz EM, Mallo GV, et al. Pancreatitis-associated protein I (PAPI), as acute phase protein induced by cytokines. J Biol Chem 1995;270:22417-22421.

34. Bishnupuri KS, Luo Q, Murmu N, et al. Reg IV activates the epidermal growth factor receptor/Akt/AP-1 signaling pathway in colon adenocarcinomas. Gastroenterology 2006;130:137-149.

35. Figdor CG, van Kooyk Y, Adema GJ. C-type lectin receptors on dendritic cells and Langerhans cells. Nat Rev Immunol 2002;2:77-84.

36. Kilpatrick DC. Animal lectins: a historical introduction and overview. Biochim Biophys Acta 2002;1572:187-197. 